\title{
Use Of Hand-Held Devices With First Year Associate Degree Nursing Students
}

\author{
Vicky K. Parker, Ohio University School of Nursing, USA \\ Lisa Kauffman, Ohio University School of Nursing, USA \\ Charlotte McManus, Ohio University School of Nursing, USA \\ Sherleena Buchman, Ohio University School of Nursing, USA \\ Charmin Miller, Ohio University School of Nursing, USA \\ Ronald Vance, Ohio University School of Nursing, USA
}

\begin{abstract}
The use of personal digital assistants (PDAs), hand-held devices and/or IPod Touches, is becoming widespread in the health care field. Many medical and nursing schools require their students to purchase a PDA prior to the beginning of their classes. PDA's can carry information directly to the patient's beside for instant retrieval of information. What does this mean to nursing students and clinical instructors? It means that up-to-date information is available to the student and clinical instructor in seconds, as opposed to searching for a reference book only to find it is outdated and 10 to 15 minutes of valuable time lost. This study identified associate degree nursing students' use and application in the clinical using PDAs. Results of this study indicated that associate degree nursing students are very satisfied with the use of PDAs in the clinical setting. This study was funded by the Ohio University Regional Faculty Research Fund.
\end{abstract}

Keywords: Personal Digital Assistants (PDAs); Handheld Devices; Accessing Current Medical Information; Reducing Medical Errors

\section{INTRODUCTION}

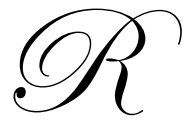

safety.

educing health care errors in patient care is an important concern to nursing educators because educators expect to generate competent nursing graduates. Therefore, educating competent, practicing nursing is the outcome criteria of quality nursing schools, while maintaining patient

Since their inception in the mid 1990's, PDAs have evolved from devices utilized primarily by business professionals to organize and track contacts, schedules, and business expenses to being used by a variety of professional fields. Particularly, the use of PDA's by health care professionals has become increasingly popular (Martin, 2003, Stroud, Erkel, \& Smith, 2005). A PDA has been identified as a useful reference tool in nursing clinical practice as a means to provide a hand-held reference library for drug and diagnostic information, and facilitate clinical decision-making at the point of care (Santori, 2008). Traditionally, these references were provided in textbooks, but in today's healthcare climate of limited clinical space and time-constrained faculty, the feasibility of having current, pertinent reference materials conveniently located for students' use has diminished. Not diminished is the need for safe nursing professionals equipped with evidence-based guidelines and current drug information to facilitate competent and accurate patient care in diverse healthcare settings.

As PDA's have become more mainstream in nursing clinical practice, nursing educators and students have also begun to recognize their value as a clinical educational tool. The researchers were challenged by restricted clinical space, as well as storage space allotted for students on clinical units. This presented a problem for students bringing textbooks, references and laptops into the clinical setting. Recognizing the potential for PDA utility with Associate Degree Nursing (ADN) students, this study was designed to describe the perceptions and use of first quarter ADN students utilizing PDAs with medical dictionary and drug information software as opposed to traditional reference materials in the clinical setting. 


\section{LITERATURE REVIEW}

Health care settings have implemented technology to decrease patient care errors by implementing the use of computers to input physician orders, diagnostic tests, and bedside charting. Trends in healthcare indicate that clinical decisions need to be based on accurate, current information, growing complexity of patients, and less time spent with the patient (George \& Davidson, 2005; Santori, 2008). With the advent of PDAs, this literally has put technology in the nurse's hands.

Medication errors are one example of a priority safety concern for nurses and nursing students. There are an estimated 7,000 Americans reported to die annually from prescription medication errors (Santori, 2008). The Institute for Safe Medication Practices has recommended use of electronic-based prescriptions and information sources to assist in reducing these numbers (Santori, 2008). The information that can be accessed at the point of care by the PDA may prove to be valuable to give reference information in achieving this goal. This is applicable to the use of the devices by nursing students to provide a beginning point to utilize this technology.

A PDA or hand-held device can be used effectively as a resource for learning, as well as a ready-reference for current, accurate clinical information. Students show an evidence of learning by increasing the numbers of clinical based questions that are pertinent to the clinical situation and accessing information on the PDA as a reference. This has been shown to be a credible resource for information as well as increasing the speed with which accurate information is obtained (Miller et al., 2005). The student's ease with the use of PDAs or hand-held devices increases the satisfaction level of actively accessing information. Therefore, PDAs or hand-held devices can assist in reducing patient care errors by using reference software such as pharmacology programs, drug calculation formulas, and clinical guidelines.

\section{METHODOLOGY}

The purpose of this study was to evaluate the use and application of PDAs in the clinical setting as an alternative to using traditional reference materials. This study utilized a convenient sample of first year associate degree nursing clinical students $(n=34)$. A 15 -item questionnaire was designed for the pre-survey and a 21 -item questionnaire was designed for the post survey of the participants. The questionnaires were developed from a review of the literature describing the use of PDAs by health professionals. Data was analyzed using descriptive statistics. Demographic data were collected, such as age, gender, employment status and previous education status. Reliability and validity data were not available. Content validity of the questionnaires was established by asking faculty members who used PDAs to evaluate the tool for content validity. The students received a two-hour instruction session prior to using the PDAs. Two software programs were available on each student's PDA - a nursing drug reference book and a reference text. Nursing faculty believed it was best to start with a small number of programs and measure their success before purchasing more software.

\section{RESULTS}

The expected result of the study was to have readily accessible, up-to-date information pertaining to their patient's care, when needed, by the student(s). As previously noted, it is often difficult and time-consuming for a student to locate a reliable reference when a question arises at the bedside. In addition, having the information within the PDA, the student did not have to remember to bring heavy reference books in their book bags each week.

Two software programs were available on each student's PDA - a nursing drug reference book and a reference text. Nursing faculty believed it was best to start with a small number of programs and measure their success before purchasing more software.

\section{Pre Survey Data}

The students were first introduced to the use of the PDA in their first quarter Foundations course. Thirtyfour, first quarter associate degree nursing students participated in the pre-survey data collection. The pre survey data consisted of 15 questions. The first part of the survey asked for demographic data, the second set of questions 
asked about personal use of a PDA, and the final set of questions asked about the benefits of using a PDA. There was also a place for comments at the end of the questionnaire. The summary of the demographic data demonstrated that the majority taking the survey were female, Caucasian, and 39 years old or younger. Of the respondents, $82.4 \%$ had completed some college classes or held a college degree (see Table 1).

Table 1: Pre Survey Demographics $(\mathrm{N}=34)$

\begin{tabular}{|l|r|}
\hline \multicolumn{1}{|c|}{ Demographics } & $\mathbf{1 0 0 \%}(\mathbf{N = 3 4 )}$ \\
\hline Female & $94.0 \%$ \\
Male & $6.0 \%$ \\
Caucasian & $100.0 \%$ \\
Hispanic & $0.0 \%$ \\
Other nationality & $0.0 \%$ \\
Employed & $88.0 \%$ \\
Full Time Student & $73.6 \%$ \\
Some College & $82.4 \%$ \\
\hline
\end{tabular}

The results of the pre survey questionnaire identified that of the 34 students, $21 \%$ have owned or had access to a PDA prior to beginning this study. Reasons for using a PDA varied, as did frequency and length of use. Finally, the survey asked the students questions relating to the expected benefits for use of a PDA in the clinical/classroom setting. Eighty-five percent of respondents thought that a PDA would be useful in the clinical or classroom setting and $15 \%$ were unsure. Thus, $85 \%$ of the respondents thought a PDA would prove to be beneficial as a tool in nursing education in the clinical/classroom areas. Comments relating to the expected benefits of the PDA in the clinical/classroom setting included: 1) excited about using new equipment, 2) excited about the opportunity to experience the PDA, and 3) anxious to see what information can be gathered using a PDA.

\section{Post-Survey Data}

At the end of the third quarter of their first year, students were asked to complete a post questionnaire relating to the use and benefits of the PDA in the clinical area. The post survey consisted of 20 questions and 27 students out of 34 students completed the post questionnaire. The first part of the survey requested demographic data (see Table 2) and the remainder of the questions asked specifically about PDA use in the classroom and the clinical setting.

Table 2: Post Survey Demographics $(\mathrm{N}=34)$

\begin{tabular}{|l|c|}
\hline \multicolumn{1}{|c|}{ Demographics } & $\mathbf{1 0 0 \%}(\mathbf{N = 2 7})$ \\
\hline Female & $100.0 \%$ \\
Male & $0.0 \%$ \\
Caucasian & $92.6 \%$ \\
Hispanic & $7.4 \%$ \\
Other nationality & $0.0 \%$ \\
Employed & $48.8 \%$ \\
Full Time Student & $100.0 \%$ \\
Some College & $40.7 \%$ \\
\hline
\end{tabular}

The results of the survey indicated that $77.8 \%$ of the students thought the PDA was useful in the clinical setting and $60 \%$ thought its use positively influenced clinical efficiency (see Table 3). Close to $50 \%$ of the students stated that the PDA was most beneficial in this setting for drug referencing. Fifty-two percent of those surveyed found the PDA useful in the classroom setting, stating it was most useful in this setting for referencing information (Table 4). 
Table 3: Perception of Efficiency of Use in Clinical and Classroom Settings $(N=27)$

\begin{tabular}{|c|c|}
\hline Comfortable with use in the Clinical setting & $\begin{array}{ll}\text { Yes } & 88.9 \% \\
\text { No } & 11.1 \%\end{array}$ \\
\hline Was the PDA useful in the Clinical setting? & $\begin{array}{lc}\text { Yes } & 70.4 \% \\
\text { No } & 7.4 \% \\
\text { Undecided } & 22.2 \% \\
\end{array}$ \\
\hline Was the PDA technology useful in the clinical setting? & $\begin{array}{ll}\text { Yes } & 77.8 \% \\
\text { No } & 22.2 \% \\
\end{array}$ \\
\hline Was the PDA useful to access information at the point of care? & $\begin{array}{lc}\text { Yes } & 55.5 \% \\
\text { No } & 7.4 \% \\
\text { Undecided } & 37 \% \\
\end{array}$ \\
\hline $\begin{array}{l}\text { Did you find the use of the PDA to have an impact on your work } \\
\text { efficiency at the clinical site? }\end{array}$ & $\begin{array}{lc}\text { Yes } & 59.9 \% \\
\text { No } & 14.8 \% \\
\text { Undecided } & 22.2 \%\end{array}$ \\
\hline Was the PDA technology useful in the classroom setting? & $\begin{array}{ll}\text { Yes } & 59.3 \% \\
\text { No } & 40.7 \% \\
\end{array}$ \\
\hline
\end{tabular}

Table 4: Use of PDA at the Clinical Setting $(N=27)$

\begin{tabular}{|l|lc|}
\hline For what purpose did you mostly use your PDA at the clinical site? & Drug referencing & $48.1 \%$ \\
& Drug calculations & $3.7 \%$ \\
& Referencing other information & $22.2 \%$ \\
& All of the above & $25.9 \%$ \\
\hline For what purpose did you mostly use your PDA in the classroom setting? & Drug referencing & $11.1 \%$ \\
& Drug calculations & $3.7 \%$ \\
& Referencing other information & $44.4 \%$ \\
& All of the above & $7.4 \%$ \\
& Did not use in classroom & $33.3 \%$ \\
\hline Overall, which of the following PDA programs were beneficial to you? & Nursing drug book & $51.9 \%$ \\
& Medical dictionary & $33.3 \%$ \\
& Nursing textbook & $3.7 \%$ \\
& Other, not specified & $11.1 \%$ \\
\hline
\end{tabular}

\section{Student Comments}

Comments related to the benefits of the PDA in the clinical setting included: 1) being able to access drug information outside a patient's room is nice, 2) the PDA was handy and easy to access during busy times on the floor, and 3) it is very helpful to be able to look up unfamiliar material. Students' comments relating to the benefits of using the PDA outside the clinical setting included: 1) used mostly for drug calculations and for my calendar of events for the classroom work, 2) I think it could be used more in the classroom, especially in pharmacology, and 3) If I was unfamiliar with the definition or disease process that the teacher was discussing in class, I could quickly look it up on my PDA.

Other comments worth noting by the students included: 1)"Wonderful experience having a great reference tool, especially with trying to keep track of all the drug references and calculations! Thanks a bundle!" and 2) "Continue to use the PDA in the clinical and classroom setting. It's very beneficial and handy versus carrying many books. Also, quick access!"

Although, the above comments were positive, there were comments by students who did not feel that the PDAs were beneficial. Most students who had a comment of this nature stated that if they would have had more software on the PDA, it would have been a more useful tool

\section{LIMITATIONS}

This study is not without limitations. The study was a small, convenient sampling of students in one associate degree nursing program on a Midwestern regional campus. 


\section{CONCLUSIONS}

Healthcare has seen the immergence of technology in the clinical setting over the last decade and most recently the usage of hand-held devices, such as the PDA, growing in popularity within the field of nursing due to its portability and ease of usage. The introduction of PDAs in the ADN program permitted students to remain mobile while keeping vital information in the palm of their hands. Students were able to carry few reference items with them to the clinical setting, which proved to be a plus with space for storage and student working being limited. Another benefit has been that students possessed the ability to look up information at the point of care, thus ultimately saving time and unneeded steps. Students recommended that the PDAs/hand-held devices should continue to be a part of the clinical experience.

Since the conclusion of this study, the faculty is requiring students to purchase an I Pod Touch as part of a book package in their first year of nursing to use during the program. Technology communication systems are growing so rapidly with the advent of IPhones, smart phones, IPod Touches, etc., that future research considerations may need to be directed toward reviewing appropriate software and patient considerations, such as safety and confidentiality.

\section{AUTHOR INFORMATION}

Vicky K. Parker, RN, PhD, FNP-BC is a faculty member with the Ohio University School of Nursing, Chillicothe campus; she teaches pediatrics in the associate degree nursing, clinical instructor for the Family Nurse Practitioner program, and the online BSN program. E-mail: parkerv@ohio.edu

Lisa Kauffman, RN, MSN, CNE is a faculty member with the Ohio University School of Nursing, Chillicothe campus; she teaches medical/surgical and physical assessment in the associate degree nursing and the online BSN program. E-mail: kauffman@ohio.edu

Charlotte McManus, RN, MSN is a faculty member with the Ohio University School of Nursing, Chillicothe campus, she teaches fundamentals in the associate degree nursing program. E-mail: mcmanusc@ohio.edu

Sherleena Buchman, RN, MSN is a faculty member with the Ohio University School of Nursing, Athens campus, as the nursing lab supervisor in the BSN program. E-mail: buchmans@ohio.edu

Charmin Miller, RN, MSN is a faculty member with the Ohio University School of Nursing, Chillicothe campus, she teaches mental nursing and pharmacology in the associate degree nursing program. E-mail: millerc3@ohio.edu

Ronald Vance, RN, MSN is a faculty member with the Ohio University School of Nursing, Chillicothe campus, he teaches medical/surgical in the associate degree nursing program. E-mail: vancer1@ohio.edu

\section{REFERENCES}

1. George, L. \& Davidson L. (2005). PDA use in nursing education: Prepared for today, poised for tomorrow. Online Journal of Nursing Informatics. 2005; 9(2). Retrieved from the website http://ojni.org/9 2/george.htm

2. Martin S. (2003). More than half of physicians under age 35 now using PDAs. CMAJ. 169: 952.

3. Stroud SD, Erkel EA, Smith CA..(2005). Journal of the American Academy of Nurse Practitioners, 17 (2): 67-75.

4. Miller J., Shaw-Kokot J., Arnold M., Boggin T., et al. (2005). A study of personal digital assistants to enhance undergraduate clinical nursing education. Journal of Nursing Education, 44(1):19-26.

5. Santori, C. (2008). The use of personal digital assistants in clinical practice. Med-Surg Matters, 17(2):9-11. 
NOTES 